\title{
Burkina Faso: Upgrading postabortion care benefits patients and providers
}

Frontiers in Reproductive Health

Follow this and additional works at: https://knowledgecommons.popcouncil.org/departments_sbsr-rh

Part of the International Public Health Commons, Public Health Education and Promotion Commons, and the Women's Health Commons How does access to this work benefit you? Let us know!

\section{Recommended Citation}

"Burkina Faso: Upgrading postabortion care benefits patients and providers," FRONTIERS OR Summary. Washington, DC: Population Council, 2000. 


\section{Burkina Faso Postabortion Care}

OR Summary 3

\section{Upgrading Postabortion Care Benefits Patients and Providers}

\begin{abstract}
Training hospital staff to improve emergency medical care for women with miscarriages and unsafe abortions leads to better patient care, shorter hospital stays, lower costs, and increased contraceptive use. Local anesthesia is essential for pain control. Physicians trained to provide postabortion care have trained other medical teams in Burkina Faso as well as in Senegal, Guinea and Haiti. Health officials from other West African countries have expressed interest in PAC training.
\end{abstract}

\section{Background}

At the request of the Family Health Directorate of the Ministry of Health $(\mathrm{MOH})$, the Reproductive Health Research Network (CRESAR) conducted a study during 1996-1998 to introduce emergency care for women with complications from miscarriage or unsafe abortion. With technical assistance from Population Council and JHPIEGO, CRESAR trained staff at two large hospitals in Ouagadougou and Bobo-Dioulasso to provide postabortion care (PAC). Training for physicians, nurses and midwives covered manual vacuum aspiration (MVA), family planning methods, infection prevention, and communication with patients. Staff also participated in the development of policies and standards for PAC services.

To measure changes in knowledge and behavior, CRESAR interviewed 330 patients with abortion complications and 78 providers before the intervention, and 456 patients and 41 providers after the intervention. Information on hospital costs was also collected.

\section{Scaling Up}

During the pilot study the $\mathrm{MOH}$, CRESAR, and service providers at the two study sites drafted national policies and standards for PAC services. The standards specify essential components of quality PAC services, such as infection prevention procedures and routine patient counseling. The $\mathrm{MOH}$ has adopted these policies and standards and has begun to extend services to regional hospitals.

The four physicians trained during this study have trained other medical teams in regional hospitals in Burkina Faso. They have also trained providers in Senegal, Guinea and Haiti. Health officials from other West African countries have expressed interest in PAC training. 


\section{Findings}

Patient satisfaction was significantly higher after improved PAC services were introduced. Nearly all patients stated that providers answered their questions readily and gave clear explanations and instructions.

- Nearly all patients (94\%) received family planning counseling. After counseling, 83 percent of the patients accepted a contraceptive method, compared with 57 percent before the intervention.

Verbal reassurance alone is inadequate for pain control during MVA. Local anesthesia is essential.
- Providers switched to MVA as their preferred treatment for postabortion care. MVA lowered costs for both the hospital and patients due to shorter hospital stays, less anesthesia, and less staff time, compared with previous clinical practices.

\section{Policy Implications}

- During expansion of PAC services, special attention should be given to quality of care and linkages to family planning services. Costs for MVA equipment and other supplies should be included in hospital budgets.

- The hospitals used as study sites can play a key role as reference, training and study centers for other practitioners.

\section{Benefits of Improved PAC Services}

\begin{tabular}{lcc}
\hline & $\begin{array}{c}\text { Before } \\
\text { Training }\end{array}$ & $\begin{array}{c}\text { After } \\
\text { Training }\end{array}$ \\
\hline Staff time for emergency treatment (minutes) & 73 & 23 \\
\hline Length of hospital stay (hours) & 36 & 19 \\
\hline Cost to patient (USD) & $\$ 34$ & $\$ 15$ \\
\hline Patient informed of immediate return of fertility & $13 \%$ & $90 \%$ \\
\hline Patient received FP method & $57 \%$ & $83 \%$ \\
\hline
\end{tabular}

Ministry of Health, Burkina Faso, 1988. Introduction of Emergency Medical Treatment and Family Planning Services for Women with Complications from Abortion in Burkina Faso. For more information contact: Population Council, 128 Sotrac Mermoz,P.O. Box 21027, Dakar, Senegal.Tel.221-824-1993; Fax: 221-824-1998; E-mail: pcdakar@pcdakar.org.

This project was conducted with support from the U.S. AGENCY FOR INTERNATIONAL DEVELOPMENT under Contract Number CCP-3030-C-00-3008-00 and Cooperative Agreement Number HRN-A-00-98-00012-00. 